\title{
Experimental characterisation on the behaviour of PLLA for stretch blowing moulding of bioresorbable vascular scaffolds
}

\author{
Huidong Wei ${ }^{1} \cdot$ Gary Menary ${ }^{1}$ (D) $\cdot$ Fraser Buchanan ${ }^{1} \cdot$ Shiyong Yan $^{1} \cdot$ James Nixon $^{1}$
}

Received: 8 July 2019 / Accepted: 9 January 2020 / Published online: 17 January 2020

(C) The Author(s) 2020

\begin{abstract}
Processing tubes from poly (l-lactic acid) (PLLA) by stretch blow moulding (SBM) is used in the manufacture of bioresorbable vascular scaffolds (BVS) to improve their mechanical performance. To better understand this processing technique, a novel experimental setup by free stretch blow inside a water bath was developed to visualise the tube forming process and analyse the deformation behaviour. PLLA tubes were heated, stretched and blown with no mould present inside a temperature-controlled water bath whilst recording the processing parameters (axial force, inflation pressure). The onset of pressure activation relative to the axial stretch was controlled deliberately to produce a simultaneous (SIM) or sequential (SEQ) mode of deformation. Realtime images of the tube during forming were captured using high speed cameras and the surface strain of the patterned tube was extracted using digital image correlation (DIC). The deformation characteristics of PLLA tubes in SBM was quantified by analysis of shape evolution, strain history and stress-strain relationship.
\end{abstract}

Keywords Experimental characterisation $\cdot$ PLLA $\cdot$ Free stretch blow $\cdot$ Water bath $\cdot$ DIC

\section{Introduction}

Poly (L-lactic acid) (PLLA) is a biodegradable polymer typically used as the base material for manufacturing bioresorbable vascular scaffolds (BVS) [1-5]. PLLA based BVS offer significant advantages over permanent metal scaffolds due to their ability to provide a temporary scaffold that resorbs once the artery has healed. These properties enable the scaffold to reduce the risk of late stent thrombosis and provides more options for future potential repeated interventional treatment $[6,7]$. One weakness of PLLA BVS is the poor mechanical performance due to the inadequate stiffness, strength and ductility of PLLA, resulting in thicker struts $(\sim 150 \mu \mathrm{m})$ compared to metal stents $(\sim 80 \mu \mathrm{m})$, which significantly limits its clinical applications [8-10]. One widely used approach to fabricate PLLA BVS is to perform laser cutting on a PLLA tube to obtain the scaffold pattern by a femtosecond laser [11, 12], achieving very high resolution $(<100 \mathrm{~nm})$ with negligible

Gary Menary

g.menary@qub.ac.uk

1 School of Mechanical and Aerospace Engineering, Queen's University Belfast, Belfast BT9 5AH, UK formation of a heat-affected zone (HAZ) [13] hence the mechanical properties of PLLA tubes have a primary influence on the final performance of products [5].

PLLA material processed by melting or solution state usually has low tensile modulus, strength and elongation to break. However, its mechanical properties can be significantly improved by altering the morphology by a secondary mechanical stretch in its semi-solid state above the glass transition temperature $\left(\mathrm{T}_{\mathrm{g}}\right)\left(>60^{\circ} \mathrm{C}\right)[14-17]$. In order to take advantage of this feature, stretch blow moulding (SBM) was introduced in the fabrication of PLLA BVS $[2,18,19]$. In this operation, thick walled tubes were prepared by extrusion $[18,20]$ or dip coating $[19,21,22]$ and subsequently processed into a parison (or preform) shape. The tube parison was heated in a mould to temperatures just above the glass transition temperature $\left(\mathrm{T}_{\mathrm{g}}\right)$ but below the thermal crystallisation temperature $\left(\mathrm{T}_{\mathrm{cc}}\right)$ and biaxially deformed by applying internal pressure and axial stretch [23]. The biaxial deformation altered the material morphology and microstructure [24] and hence enhanced the mechanical properties (stiffness, strength and ductility) $[18,25$, 26].

A combination of temperature, pressure, and stretch is needed for the application of stretch blow moulding. Of these conditions, processing temperature $\left(\mathrm{T}_{\mathrm{p}}\right)$ for stretch blow moulding of PLLA scaffolds has typically been performed at 
$10 \sim 20{ }^{\circ} \mathrm{C}$ or $20 \sim 40{ }^{\circ} \mathrm{C}$ above $\mathrm{T}_{\mathrm{g}}\left(\sim 60{ }^{\circ} \mathrm{C}\right)$ [18]. The tube parison can be heated inside a hot mould by convection [26] or radiation [24] at a controlled heating time. Processing temperature has previously been observed to influence the tensile modulus and strength when compared at the same hoop strain level [27] and the strain level mainly determined the final orientation [26]. The operational sequence is another influence factor, i.e. supplying axial stretch and pressure simultaneously (SIM) or sequentially where the material was initially stretched in the axial direction and subsequently inflated in the hoop direction (SEQ). It was found that there was less anisotropy in the SEQ process indicated by balanced hoop and axial modulus and yield strength at low axial strain rate $\left(\sim 0.2 \mathrm{~s}^{-1}\right)$ $[26,28]$. Although the literature highlights the relevance of processing conditions with the blown tubes, there is little information on the actual strain rate occurring during blowing and the evolution of hoop and axial strain during forming.

Previous research on stretch blow moulding has offered different approaches to better understand the forming process. By using a transparent mould, the shape evolution of preforms in the blowing process was recorded by high speed cameras for PET bottles [29] and PA-12 angioplasty balloons [30]. The disadvantage of inspecting blowing inside the mould is the lack of accurate quantitative data during deformation. An approach that removes the mould to perform 'free blow' was subsequently proposed [31] and enabled the measurement of surface strain by digital image correlation (DIC) [32-34]. The stress during deformation was calculated based on the measured processing parameters (pressure, reaction force) during stretching [35]. In free blow, the preforms were heated firstly to the desirable temperature, transferred to a blowing station and blown in air without the mould. However the time dependent temperature profile of preforms need to be accounted for due to the complexity of the coupling between the thermal and mechanical properties [32, 34].

Based on the successful investigation of stretch blow moulding by free stretch blow for PET bottles [32-36], this article describes a technique for characterising the behaviour of PLLA tubes for stretch blow moulding of BVS. A novel experimental setup by processing tubes within a water bath has been introduced to ensure isothermal conditions, overcoming the surface cooling problems from exposure in the atmosphere during transfer from heating station to blow station. Along with this approach, a test rig was developed to conduct the stretching and blowing operation whilst recording processing parameters (axial force, inflation pressure) with incorporated sensors. Digital image correlation (DIC) was employed to acquire accurate evaluation of the surface strain by analysing deforming images of the tube parison. With a combination of the pressure, force and strain field, the stressstrain relationship of the PLLA material can be acquired directly from the tube and provide an insight into how this stress-strain behaviour changes with processing conditions.
Thus a methodology to characterise the behaviour of the PLLA material directly from the parison is developed.

\section{Experimental setup}

\section{Tube preparation}

Pellets of PLLA (Tradename: PURAPOL LX175) were supplied by Corbion PURAC (Amsterdam, The Netherlands) with $96 \%$ L-isomer of stereochemical purity and weightaverage molecular weight $\left(\mathrm{M}_{\mathrm{w}}\right)$ of $14.25 \times 10^{4} \mathrm{~g} / \mathrm{mol}$. The PLLA pellets were melted and extruded into tubes by a KILLION single screw extruder with a pin of $5.4 \mathrm{~mm}$ and die of $10.5 \mathrm{~mm}$. The temperature of the extrusion barrel ranged from $175{ }^{\circ} \mathrm{C}$ to $194{ }^{\circ} \mathrm{C}$ whilst the rotation speed of the extruder was set at $15.0 \mathrm{rad} \cdot \mathrm{min}^{-1}$. The extruded tubes were precisely calibrated by a vacuum calibrator and by a drawing machine operating at a speed of $7.26 \mathrm{~m} \cdot \mathrm{min}^{-1}$. They were quenched by a water bath in a long $(\sim 2 \mathrm{~m})$ tank to ensure an amorphous state which was confirmed by an initial crystallinity of $3.0 \%$ via a DSC test. The final extruded tubes had dimensions of $4.0 \pm 0.1 \mathrm{~mm}$ outside diameter (OD) and $1.00 \pm 0.03 \mathrm{~mm}$ wall thickness (WT).

In the lab operation, the extruded PLLA tubes (OD: $4 \mathrm{~mm}$, WT: $1 \mathrm{~mm}$ ) were cut into pieces with a length of $105 \mathrm{~mm}$, producing specimens with a central part of $20 \mathrm{~mm}$ and two ends of length equal to $60 \mathrm{~mm}$ and $20 \mathrm{~mm}$ (Fig. 1a). The extruded PLLA tubes were further processed into a parison shape with two pre-stretched ends as is typically done for the stretch blow moulding of angioplasty balloons $[37,38]$. Each end of the tube was immersed in a silicone oil bath of $100{ }^{\circ} \mathrm{C}$ for two minutes and then stretched to a ratio of 5.0 within $10 \mathrm{~s}$. The stretched tube was trimmed at each end to leave $60 \mathrm{~mm}$ at one end and $20 \mathrm{~mm}$ at the other end to create a tube parison (Fig. 1b). The purpose of this preparation was to leave an effective length of the tube at the original dimension that ultimately was stretched and blown. Orientation and crystallization $(\sim 30 \%)$ were introduced at the two ends with enhanced stiffness to avoid these sections being inflated.

\section{Experiment design}

A schematic diagram of the equipment for the free stretch blow of the PLLA tubes is shown in Fig. 2. The PLLA tube parison was heated and formed inside a water bath in a glass tank. A thermostatic heating circulator with temperature display and control was employed to heat the water to the desired temperature. Compressed air was supplied with the pressure regulated to a desirable level. The pressure activation was controlled by a solenoid valve. A test rig capable of standing 


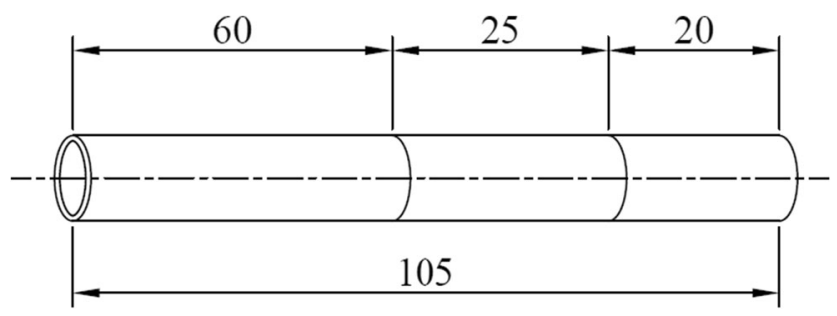

(a)

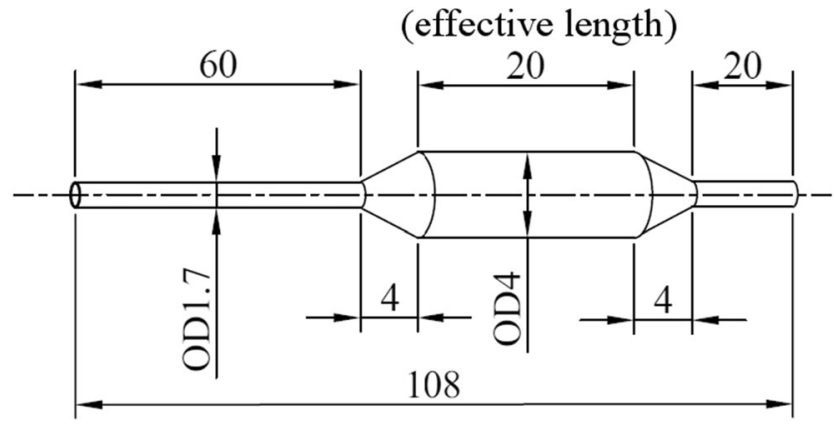

(b)

Fig. 1 Dimensions of PLLA tubes (unit: $\mathrm{mm}$ ), (a) original tube, (b) tube parison

vertically in the water tank was built to conduct the stretching operation without a mould to visualize the forming process. The pressure and axial force were measured by a pressure sensor at working pressure from 0.0 to $1.2 \mathrm{MPa}$ and a load cell with a maximum force limit of $250 \mathrm{~N}$ respectively. A programmable microcontroller (Arduino Mega 2560) with a user interface (LCD terminal) was used to conduct the process

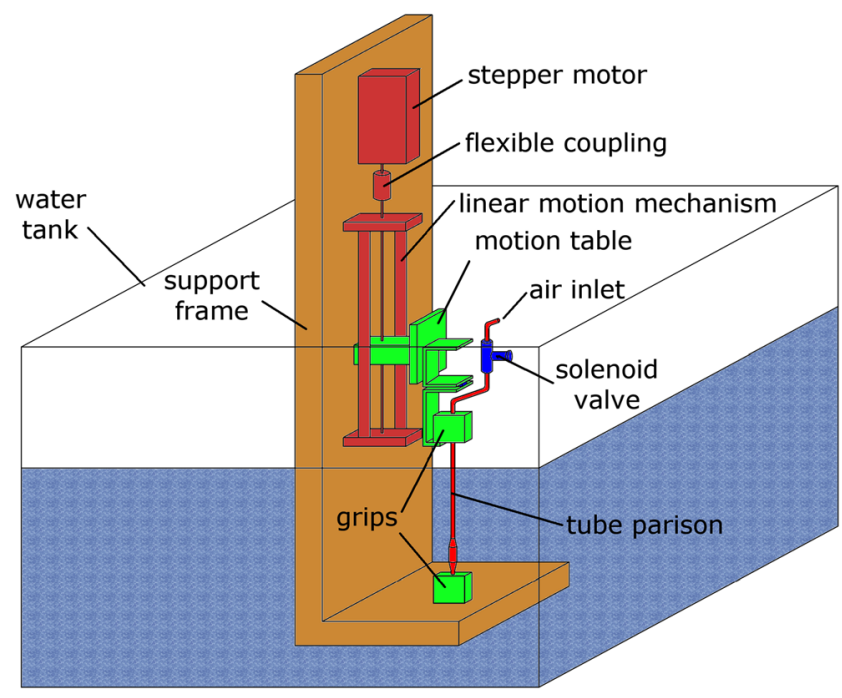

Fig. 3 Test rig arrangement in water bath

control and data collection. The tube forming process was monitored by two high speed cameras.

The details of the test rig are shown in Fig. 3. The tube parison was installed between two grips where the top end grip was connected to a motion table mounted on the shaft and driven by a stepper motor whilst the bottom grip was fixed on a support frame. An initial axial stretch $(\sim 6 \mathrm{~mm})$ within $0.3 \mathrm{~s}$ was used to provide axial tension on tubes to avoid sagging as the sample heated. The maximum stretching distance of the motion table from the stepper motor was $60 \mathrm{~mm}$ whilst a maximum speed of $25 \mathrm{~mm} \cdot \mathrm{s}^{-1}$, allowing for a total forming time of $2.5 \mathrm{~s}$. Considering the initial effective length of $20 \mathrm{~mm}$ of the tube parison, the stepper motor was able to provide a maximum possible axial strain of 2.0 at an average strain rate of $1.3 \mathrm{~s}^{-1}$. The amount of initial axial stretch was varied by modifying the timing of the application of the
Fig. 2 Experimental setup

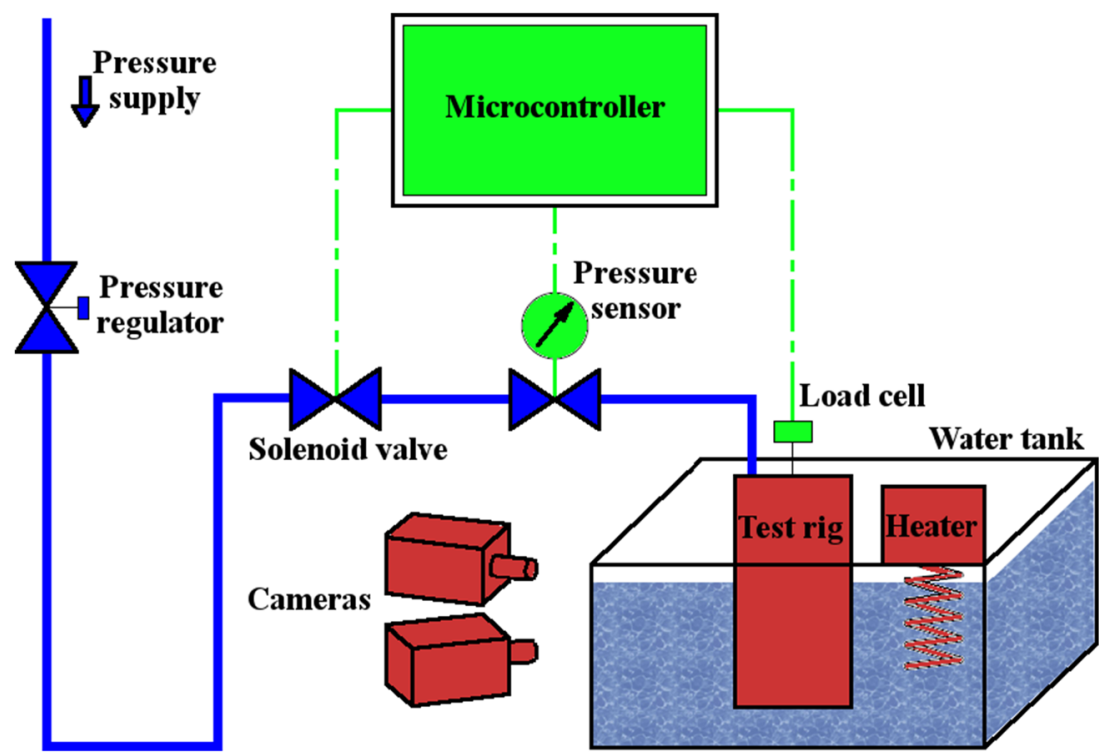


pressure. In order to provide a simultaneous deformation process (SIM), the timing of the onset of pressure was set at a value of $0.3 \mathrm{~s}$, following the initial axial deformation whilst the timing was increased to a value of $1.3 \mathrm{~s}$ to supply a sequential (SEQ) deformation process by applying an initial larger axial strain ( 1.7). During the pressure supply, a constant pressure value of 6.0 bar was provided for a time of $2.0 \mathrm{~s}$, accomplishing the inflation process without the specimen bursting. Two processing temperatures $\left(T_{p}\right)$ were selected at $\mathrm{T}_{\mathrm{p}}=72{ }^{\circ} \mathrm{C}$ and $\mathrm{T}_{\mathrm{p}}=77^{\circ} \mathrm{C}$, within the range of $10 \sim 20{ }^{\circ} \mathrm{C}$ above $\mathrm{T}_{\mathrm{g}}\left(\sim 60^{\circ} \mathrm{C}\right)[23]$. Overall 4 blowing cases, which were defined as T72SIMP6, T72SEQP6, T77SIMP6, T77SEQP6 were studied in the free stretch blow experiment.

\section{Digital image correlation}

The technique of digital image correlation (DIC) calculates the strain field on the external surface of an object by comparing the grayscale of captured images during the deformation process, where a subset with points is tracked by building a correlation on the grey values [39]. To employ this technique, the surface of PLLA tubes along the $20 \mathrm{~mm}$ effective length was painted thoroughly with a white background by a permanent paint marker. A random black speckle pattern in the foreground was applied by an acrylic spraying aerosol (Fig. 4a). A black rubber O-ring was installed on the top cone region of the tube parison to mark the effective height of tube. Two Photon Fastcam SA1.1 high speed cameras with resolution of $1024 \times 1024$ pixels at a frame rate of 1000 frames per second (fps) were used to set up a stereo DIC on a fixed support. LED panels were used to provide the necessary lighting. A Tokina $100 \mathrm{~mm}$ F2.8 AT-X Macro Lens was installed on each camera to adequately observe the scale of the speckle pattern. The lens had a full coverage of $35 \mathrm{~mm}$ with the closest focusing distance of $300 \mathrm{~mm}$ that yields a 1:1 reproduction ratio. A calibration process was performed after setting up the configuration of DIC by using the painted plate with $3 \mathrm{~mm}$ dots immersed in water to obtain the configuration parameters before experiment (Fig. 4b). The commercial software Vic-3D (Correlated Solutions, US) was used to analyse the captured images during forming, based on the parameters in the DIC setup (Table 1).

\section{Deformation assessment}

\section{Strain extraction}

Only the effective length of the tube parison was subjected to deformation and a section of this length equal to $15 \mathrm{~mm}$ was selected for the strain measurement (Fig. 5a). The contours on Fig. 6a represent the vertical distance in $\mathrm{mm}(\mathrm{Y})$ from a reference point on the middle of the specimen marked with a label of zero. The time dependent nominal hoop and axial strain history was extracted at the zero point and at a distance of plus and minus $5 \mathrm{~mm}$ from it. In addition to DIC measurement, the average hoop and axial strain were calculated by measuring the length and diameter of tube images before and during forming manually (Fig. 5b). The deformed images at processing time of $\mathrm{t}=0.2,0.6,1.0,1.4,1.8$ and $2.2 \mathrm{~s}$ were selected to investigate the shape evolution and perform subsequent measurement. The average hoop strain is calculated by Eq. (1) based on the initial diameter $\left(\mathrm{D}_{0}\right)$ and deformed diameter $\left(D_{1}\right)$. The average axial strain is calculated by Eq. (2) based on the initial length $\left(\mathrm{L}_{0}\right)$ and deformed length $\left(\mathrm{L}_{1}\right)$.

$$
\begin{gathered}
\varepsilon_{\mathrm{h}}^{\text {ave }}=\frac{D_{1}-D_{0}}{D_{0}} \\
\varepsilon_{a}^{\text {ave }}=\frac{L_{1}-L_{0}}{L_{0}}
\end{gathered}
$$

Fig. 4 Preparation of DIC, (a) speckle patterns on the tube, (b) calibration in water bath

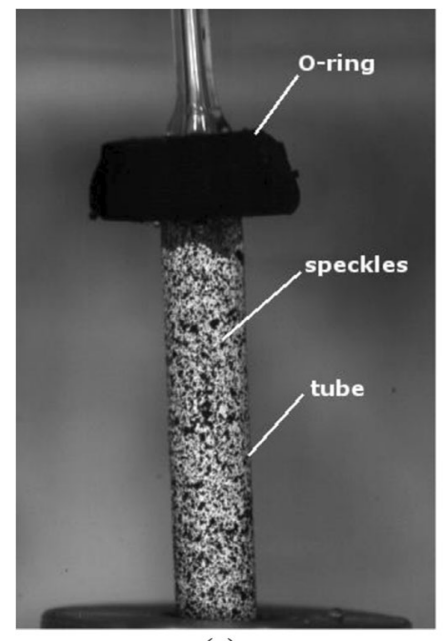

(a)

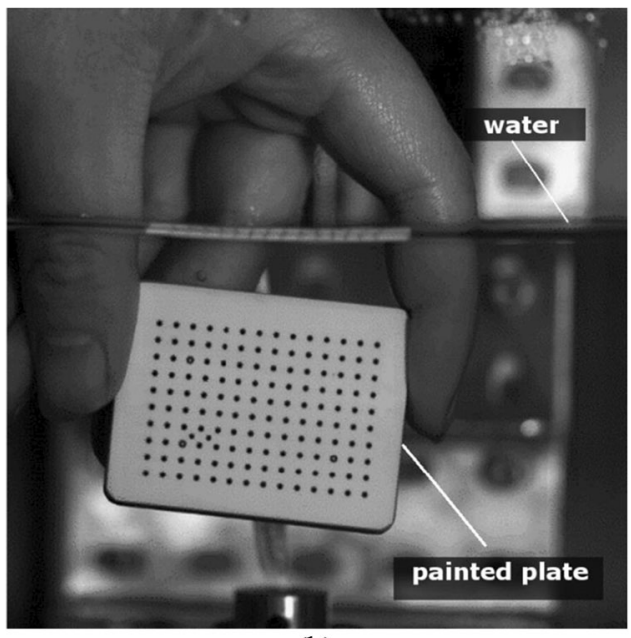

(b) 
Table 1 DIC setup details

\begin{tabular}{ll}
\hline Speckle size & $3 \sim 8$ pixels \\
\hline Subset & $29 \times 29$ \\
Step size & 1 \\
Measurement points & $7500 \sim 8000$ (approx.) \\
Camera & 12 -bit, $1024 \times 1024$ \\
Field of view & $68.5 \times 68.5 \mathrm{~mm}$ (approx.) \\
Focal length & $535 \mathrm{~mm}$ (approx.) \\
Displacement resolution & $0.6689 \mu \mathrm{m}, 0.01$ pixel \\
Correlation method & Incremental \\
Smoothing method & Gaussian filter, 15 \\
\hline
\end{tabular}

To obtain the average values of hoop strain through the wall thickness, the measured strains on the external surface were converted to the results on the middle surface based on a number of assumptions, (1) the deformation was perfectly axisymmetric [40, 41], (2) the axial strain was uniform through the thickness $[40,41]$ and (3) the material was assumed incompressible, which is a reasonable assumption for a deforming polymer with finite strain above $T_{g}$ [42]. The average hoop strain on the middle surface can be calculated by Eq. (3) and the unknown wall thickness was calculated based on the equivalent volume before and after deformation by Eq. (4). The updated external radius can be solved by the measured surface strain by Eq. (5).

$\varepsilon_{\mathrm{h}}^{\mathrm{mid}}=\frac{R-\frac{t}{2}}{R_{0}-\frac{t_{0}}{2}}-1$
$\pi\left[R_{0}^{2}-\left(R_{0}-t_{0}\right)^{2}\right]=\pi\left[R^{2}-(R-t)^{2}\right]\left(1+\varepsilon_{\mathrm{a}}^{\mathrm{ext}}\right)$

$R=R_{0}\left(1+\varepsilon_{\mathrm{h}}^{\mathrm{ext}}\right)$

Where, $\varepsilon_{\mathrm{h}}{ }^{\text {mid }}$ is the hoop strain on the middle surface; $\mathrm{R}_{0}$ and $t_{0}$ are the initial external radius and wall thickness of tubes before deformation; $\mathrm{R}$ and $\mathrm{t}$ are the external radius and wall thickness of deformed tubes during deformation respectively; $\varepsilon_{\mathrm{a}}{ }^{\text {ext }}$ and $\varepsilon_{\mathrm{h}}{ }^{\text {ext }}$ are the hoop and axial strain on the external surfaces extracted by DIC respectively.

\section{Stress calculation}

It has been reported that the contribution of inertia during forming is negligible compared to the elastic and viscous effect [43]. When the tube is long enough, the stress state of the tube can be estimated by an analytical approach without considering the boundary effect $[40,41]$. It is considered to be a closed end cylinder under internal pressure and an axial stretch (Fig. 6). Before blowing, the tube has a diameter to thickness ratio of 2.0 , placing it in a thick-walled cylinder category. This ratio changes significantly however when the tube begins to blow. It has been found that even during stretch blow moulding of PET bottles for preforms with diameter to thickness ratio of 3.0, the hoop stress can be calculated by thin walled theory due to the low initial stress values [35]. To confirm this conclusion, the stress on the middle surface is computed by two methods. Eq. (6) and (7) calculate the hoop and axial stress by the thin-walled shell theory whilst Eq. (8) and (9) calculate the hoop and axial stress based on thick-walled shell theory [44].
Fig. 5 Strain extract, (a) initial tube length $(\mathrm{t}=0)$ and data points extracted by DIC, (b) average strain by measurement

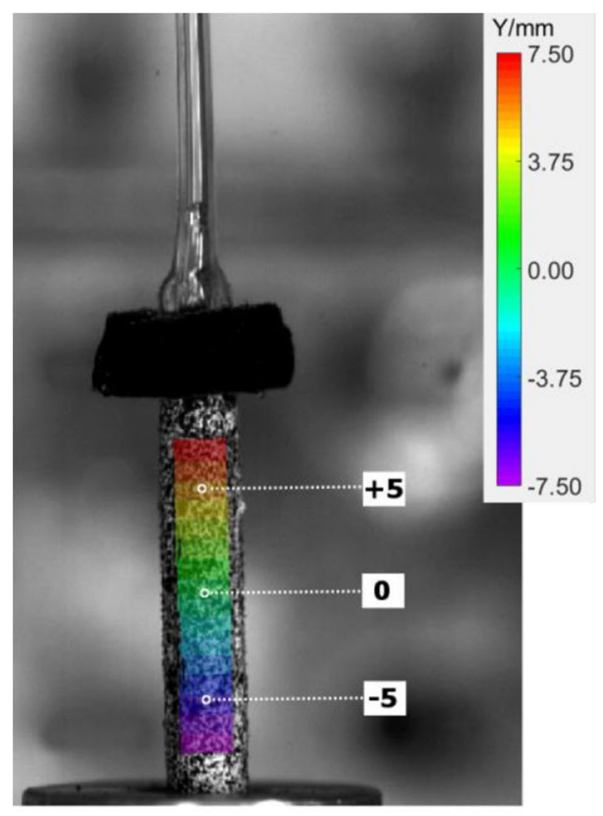

(a)

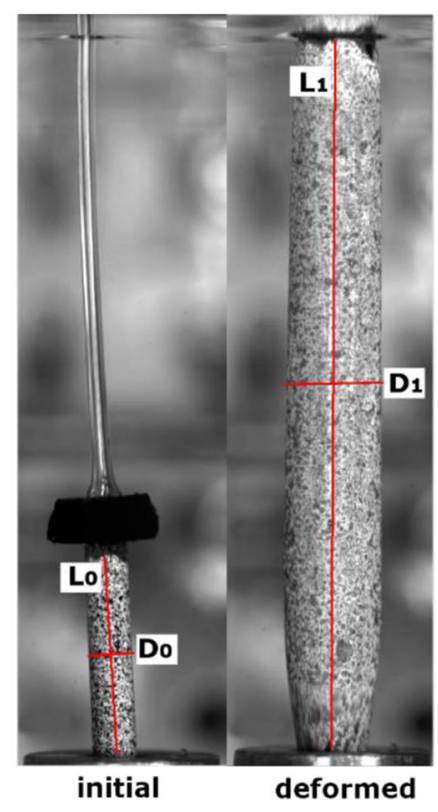

(b) 
Fig. 6 Stress state of the middle surface for the cylindrical part of the tube parison
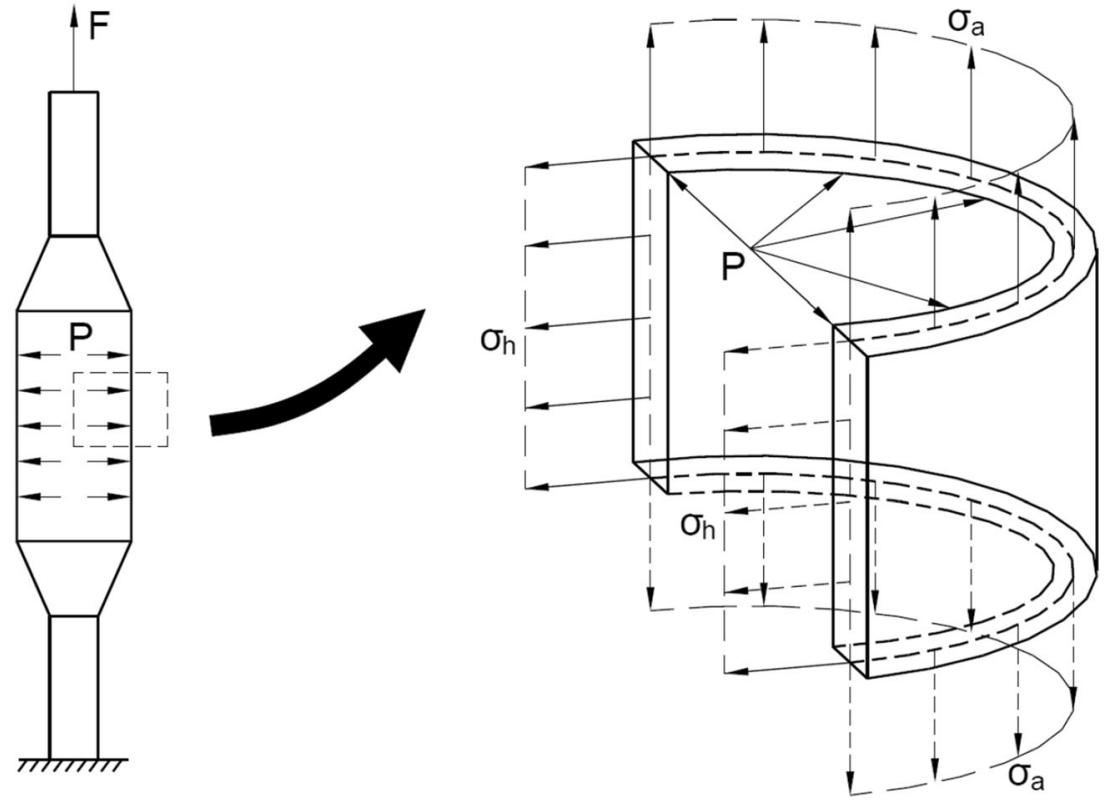

$\sigma_{\mathrm{h}}^{\mathrm{thn}}=\left(\frac{P R_{\mathrm{mid}}}{t}\right)$

$\sigma_{\mathrm{a}}^{\mathrm{thn}}=\frac{1}{2 R_{\text {mid }} t}\left[P R_{\text {mid }}^{2}+\frac{F}{\pi}\right]$

$\sigma_{\mathrm{h}}^{\mathrm{thk}}=\frac{P(R-t)^{2}}{R^{2}-(R-t)^{2}}\left[1+\frac{R^{2}}{R_{\mathrm{mid}}^{2}}\right]$

$\sigma_{\mathrm{a}}^{\mathrm{thk}}=\frac{1}{R^{2}-(R-t)^{2}}\left[P(R-t)^{2}+\frac{F}{\pi}\right]$

Where, $\sigma_{\mathrm{h}}$ and $\sigma_{\mathrm{a}}$ are the hoop and axial stress on the middle surface, with a subscript 'thk' for thick walled cylinder theory and 'thn' for thin walled theory; $\mathrm{F}$ is the axial force induced by the mechanical stretch; $\mathrm{R}^{\mathrm{mid}}, \mathrm{R}$ and $\mathrm{t}$ are the middle radius, external radius and wall thickness of the tube respectively.

\section{Results}

\section{Influence of paint on forming process}

For the case of T72SIMP6, the forming process of the original tube parison without paint was investigated and compared with the parison with the painting required for DIC (Fig. 7). It can be seen that for the original tube parison (Fig. 7a), after pressure supply at $\mathrm{t}=0.3 \mathrm{~s}$, between 0 and $1 \mathrm{~s}$ the tube is stretched axially with little or no hoop deformation however after $1 \mathrm{~s}$ an initial homogenous expansion along the tube length was observed. The formed product at $\mathrm{t}=2.2 \mathrm{~s}$ had a cylindrical shape with a diameter of $8.2 \mathrm{~mm}$. A similar evolution process was found for the tube parison with paint (white background and speckle patterns in the foreground) (Fig. 7b). The onset of inflation occurred at the same time point as the original tube $(t=1.0 \mathrm{~s})$ and further expansion showed the same characteristics. The blown product with painting at $\mathrm{t}=$

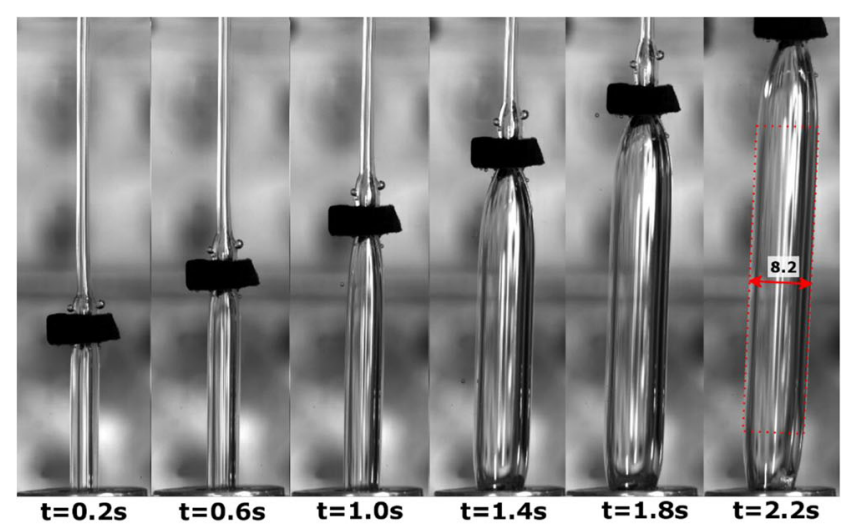

(a)

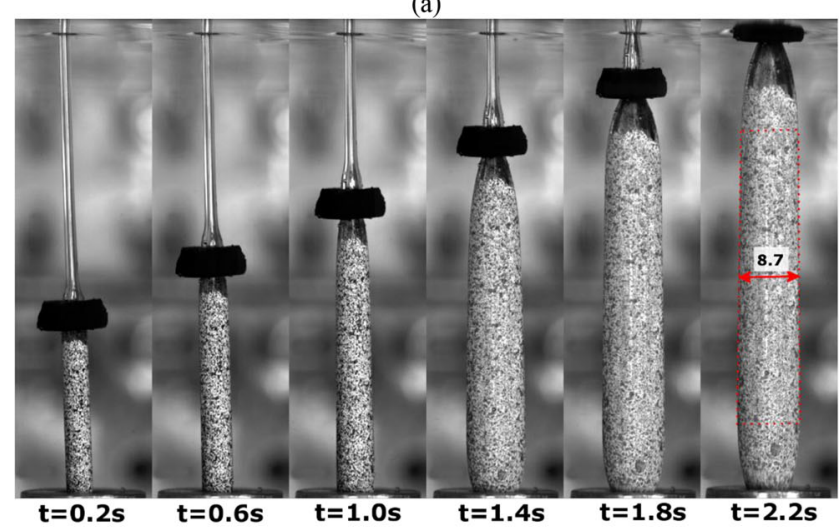

(b)

Fig. 7 Shape evolution at T72SIMP6, (a) original tube parison, (b) tube parison with speckle pattern 
$2.2 \mathrm{~s}$ exhibited a cylindrical length with a diameter of $8.7 \mathrm{~mm}$, indicating a small deviation of $6 \%$ when compared with the tube without paint. This comparison displayed the repeatability of the free stretch blow test in the experiment and the irrelevance of speckle painting to the forming process.

\section{Influence of mode of deformation}

As stated in section 3, two different modes of deformation were analysed in the free stretch blow test, (1) the case where the axial stretching and pressure were applied simultaneously - referred to as simultaneous stretching (SIM) and the case where there was an initial axial strain of 1.7 before blowing commenced, referred to as sequential stretching (SEQ). Figure 8 shows the shape evolution of the parison when stretched sequentially at $\mathrm{T}_{\mathrm{p}}=72{ }^{\circ} \mathrm{C}$ and 6 bar (T72SEQP6). In contrast to the onset of inflation for the SIM process $(\sim 1.0 \mathrm{~s})$, it can be clearly seen that all the hoop deformation in the SEQ process occurs after a time of $1.8 \mathrm{~s}$ after the axial deformation has completed.

The measured pressure and axial force data during the forming process were extracted and compared for the two tests (T72SIMP6 and T72SEQP6) (Fig. 9). The difference between the SIM and SEQ mode of deformation was clearly evident by the time shift of $1.0 \mathrm{~s}$ from the pressure supply. This is deliberate to enable a reasonable difference in the level of axial strain applied before pressurisation to initiate the SIM and SEQ deformation modes. The small drop of pressure measured after $t=2.3 \mathrm{~s}$ in the SIM process is due to a pressure release after stopping the air supply at the point when the experiment had finished.

A linear increase of axial force was observed before $\mathrm{t}=$ $0.7 \mathrm{~s}$ for T72SIMP6 (Fig. 9a) and T72SEQP6 (Fig. 9b). This indicated the initial elastic stage of the PLLA material in the small strain regime $[23,45]$. There was an initial higher axial force at T72SEQP6 as the stretch was exclusively from the motor movement whilst the stretching load was shared with the axial force from the internal pressure for T72SIMP6.

Quantitative information of the forming process was provided by analysing the tube images with digital image correlation (DIC) and average strain from manual measurement. The strain vs time in the axial and hoop directions for 3 points on the surface of the tube (as highlighted in Fig. 5a) are shown in Fig. 10. For the T72SIMP6 test (Fig. 10a), it can be seen that the evolution of strain for each location was similar. The deformation resulted in a final hoop and axial nominal strain of approximately 1.3 on the external surface. In contrast to the linear increase of axial strain at a rate of $0.5 \mathrm{~s}^{-1}$, three stages were observed in the hoop direction, which can be described by (1) onset of pressurisation time $(t=0.3 \mathrm{~s})$, (2) onset of rapid inflation $(\mathrm{t}=1.1 \mathrm{~s})$, and $(3)$ cessation of rapid inflation $(\mathrm{t}=$ $1.7 \mathrm{~s})$. Before $t=0.3 \mathrm{~s}$, the axial stretch introduced a decreasing diameter, i.e. negative hoop strain. After pressurisation $(\sim 0.3 \mathrm{~s})$, a short duration of $0.1 \mathrm{~s}$ was required for the pressure to reach the desirable level characterised by a fast increase of hoop strain. Deformation continued at low strain rate $\left(\sim 0.2 \mathrm{~s}^{-1}\right)$ until yielding at $\mathrm{t}=1.1 \mathrm{~s}$, after which a rapid inflation occurred at a maximum strain rate of $1.9 \mathrm{~s}^{-1}$. At the latter stage of inflation, the hoop strain rate decreased gradually towards zero until $\mathrm{t}=1.7 \mathrm{~s}$, where the deformation in the hoop direction significantly reduced due to the material strain hardening [23].

At T72SEQP6 (Fig. 10b), the axial strain data by DIC showed a linear increase over time but that the strain rate and the final strain was strongly dependent on the location thus indicating a non-uniform stretch along the tube in the case of large initial stretch. The average axial strain by measurement (blank circle) was found to be similar to the result at position $3(-5 \mathrm{~mm})$. The agreement of hoop strain at the three positions was observed by strain data from DIC, showing a
Fig. 8 Shape evolution at T72SEQP6

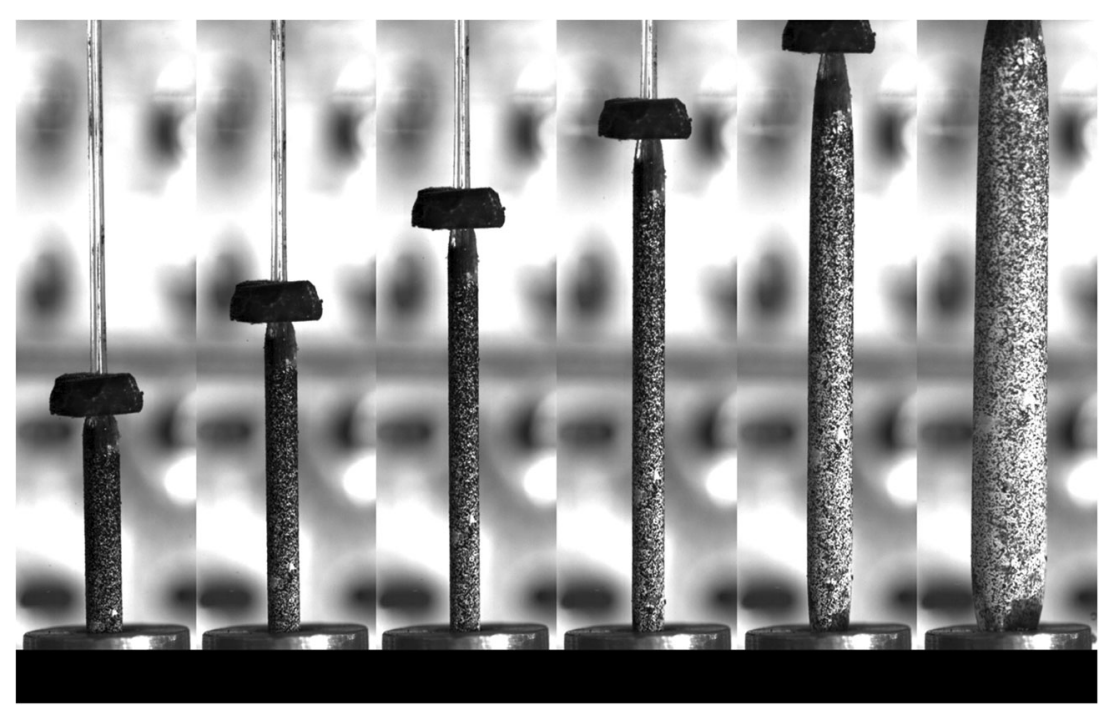


Fig. 9 Pressure (P), displacement (D) and force history (F), (a) T72SIMP6, (b) T72SEQP6

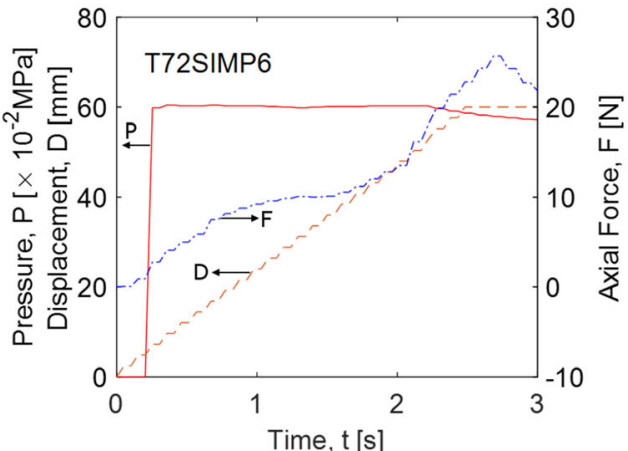

(a)

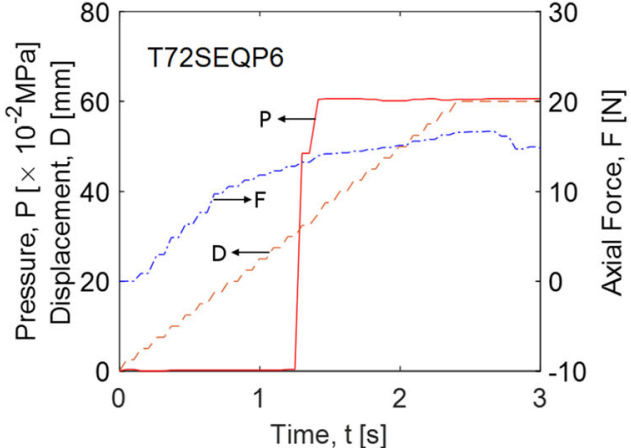

(b) maximum deviation of $7 \%$ with the average results by measurement. The deformation can be split into 3 distinct regions, i.e. uniaxial stretching for $\mathrm{t}<1.3 \mathrm{~s}$ which was indicated by the increasing axial strain with decreasing hoop strain, followed by rapid inflation ( $\mathrm{strain}$ rate $=3 \mathrm{~s}^{-1}$ ) between $\mathrm{t}=1.3 \mathrm{~s}$ and $\mathrm{t}=$ $2.3 \mathrm{~s}$ and strain hardening beyond this time point.

Based on the assumption of uniform axial strain throughout the wall thickness and consideration of constant volume, the point strain data from DIC similar to average measurement strain was selected to calculate the hoop and axial strain on the middle surface at $\mathrm{T}_{\mathrm{p}}=72{ }^{\circ} \mathrm{C}$ (Fig. 11). The hoop strain vs time for both the SIM and SEQ process showed similar qualitative behaviour to the result of the external surface but both had significantly different magnitudes. A final hoop strain of 2.1 on the middle surface was displayed for T72SIMP6 and T72SEQP6, a 50\% increase compared to the result of the external surface $(\sim 1.4)$. The maximum hoop strain rate during inflation reached $2.8 \mathrm{~s}^{-1}$ for the SIM process and $4.2 \mathrm{~s}^{-1}$ for the SEQ process, approximately $40 \%$ higher than the results as calculated from the external surface (SIM: $1.9 \mathrm{~s}^{-1}$, SEQ: $3.0 \mathrm{~s}^{-1}$ ).

\section{Increase of temperature}

At the elevated processing temperature of $\mathrm{T}_{\mathrm{p}}=77^{\circ} \mathrm{C}$, the shape evolution of the PLLA tubes was inspected for both simultaneous and sequential mode of deformation (Fig. 12). At T77SIMP6 (Fig. 12a), after the pressure was supplied at $\mathrm{t}=$ $0.3 \mathrm{~s}$, the inflation occurred at $\mathrm{t}=0.6 \mathrm{~s}$, a time interval of $0.3 \mathrm{~s}$ smaller than the T72SIMP6 test. The external diameter reached a stable size (no further increase in hoop strain) at $\mathrm{t}=1.0 \mathrm{~s}$ and a 'banana' shaped tube was observed. Since the balloon is acting as a closed end pressure vessel and hence has both an axial and hoop stress it is clear that the cause of the "banana" shape is due to the axial deformation contribution from the internal pressure deforming the tube axially at a faster rate than that capable of being produced by the stepper motor $\left(\sim 1.0 \mathrm{~s}^{-1}\right)$. Beyond this time point, the axial deformation from the internal pressure became stable. The elongation from the motor acted on the top end of the tube, enabling it to recover to a straight state at $\mathrm{t}=1.4 \mathrm{~s}$. At T77SEQP6 (Fig. 12b) however, the distortion of the tube parison was prevented. By comparing the results at $72{ }^{\circ} \mathrm{C}$ and $77^{\circ} \mathrm{C}$, the effect of temperature can be clearly seen for both the SIM and SEQ deformation mode, with an earlier onset and more rapid blowing process for the higher temperature tests.

A different evolution of axial force was illustrated between the SIM and SEQ process at $77^{\circ} \mathrm{C}$ in Fig. 13. An initial elastic stage was observed before $\mathrm{t}=0.6 \mathrm{~s}$ and subsequent slow increase of force at T77SIMP6 from $t=0.6 \mathrm{~s}$ to $1.7 \mathrm{~s}$. This was similar to the evolution of T72SIMP6 at the same time interval but showed smaller axial force due to the reduced material stiffness at high temperature [23]. Beyond 0.6 s (T77SIMP6) and $1.7 \mathrm{~s}$ (T77SEQP6), a rapid decrease of the axial force was observed, which was caused by the increase of axial force from internal pressure at a higher rate than the axial elongation from the stepper motor. The negative axial force at $t=1.0 \mathrm{~s}$ at
Fig. 10 Strain history of external surface by DIC (purple: $-5 \mathrm{~mm}$, green: $0 \mathrm{~mm}$, magenta: $5 \mathrm{~mm}$ ) and average manual measurement, (1) onset of pressurisation time, (2) onset of rapid inflation and (3) cease of rapid inflation; (a) T72SIMP6, (b) T72SEQP6
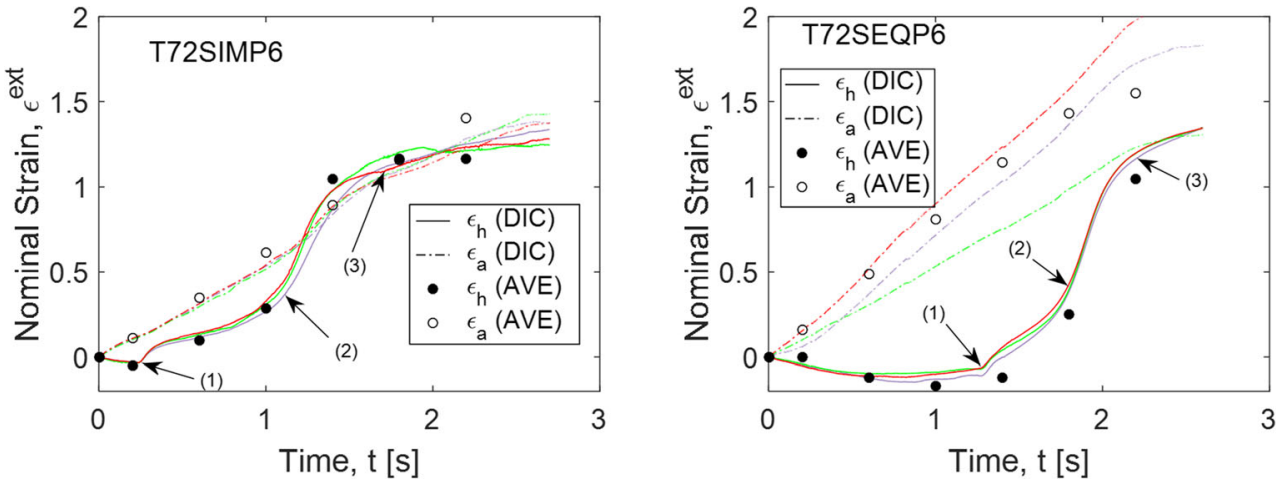
Fig. 11 Average strain history on the middle surface, (a) T72SIMP6, (b) T72SEQP6

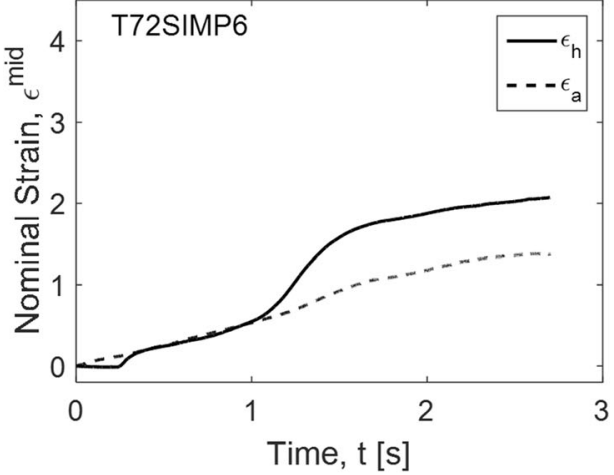

(a)

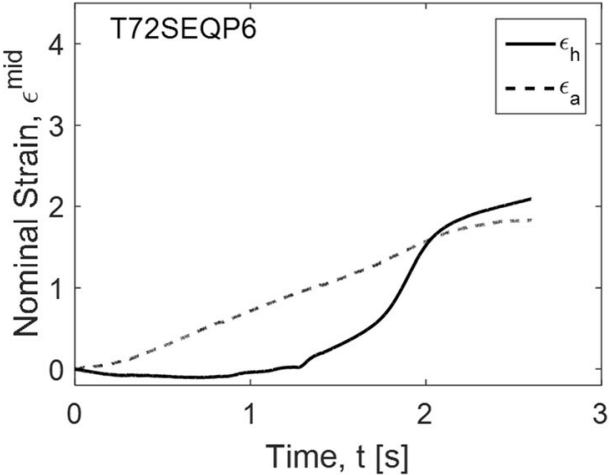

(b)
T77SIMP6 highlighted the more significant influence and overrode the axial stretch completely, corresponding to the 'banana' shaped tube parison. Comparatively, the axial force remained positive at this stage before $\mathrm{t}=1.9 \mathrm{~s}$ at T77SEQP6. After the accomplishment of hoop inflation, the axial force remained constant from $\mathrm{t}=1.0$ to $1.4 \mathrm{~s}$ at T77SIMP6, implying a duration of $0.4 \mathrm{~s}$ to re-engage the axial stretch from the stepper motor. This re-engagement became faster at T77SEQP6 taking place between $\mathrm{t}=1.9$ to $2.0 \mathrm{~s}$. In the subsequent axial stretching stage, there was a stronger

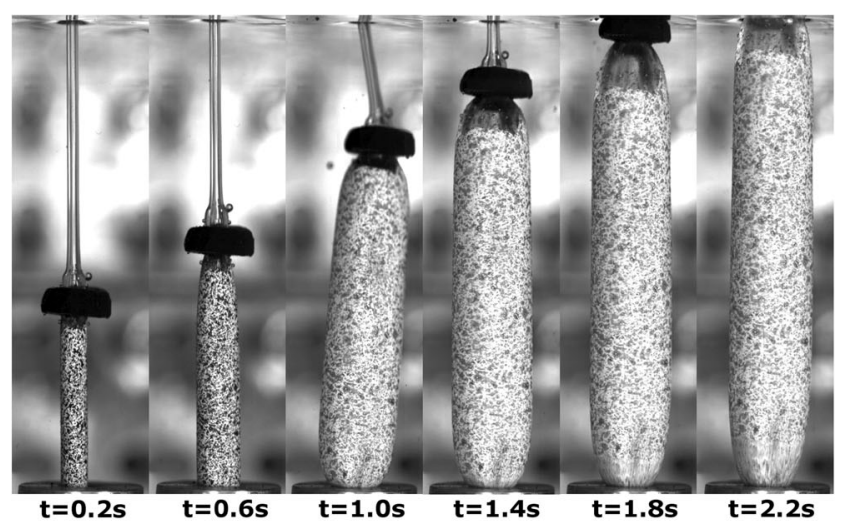

(a)

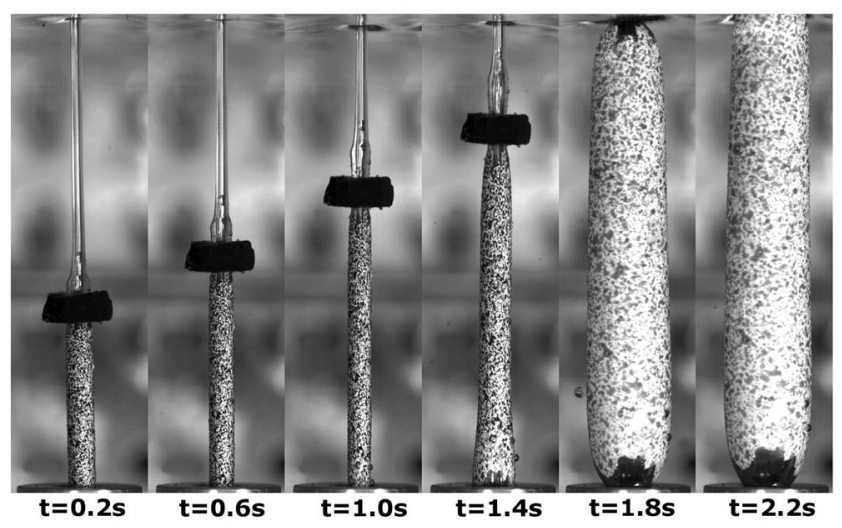

(b)

Fig. 12 Shape evolution, (a) T77SIMP6, (b) T77SEQP6 sequentially secondary stretch effect at T77SIMP6 than T77SEQP6 due to the early accomplishment of the hoop deformation for the SIM process.

The hoop and axial strain for the T77SIMP6 and T77SEQP6 tests are shown in Fig. 14. A big influence on the strain history from processing temperature was observed in both processes. After pressure supply at $0.3 \mathrm{~s}$ (T77SIMP6) and $1.3 \mathrm{~s}$ (T77SEQP6), a hoop strain rate of $0.8 \mathrm{~s}^{-1}$ (SIM) and $2.5 \mathrm{~s}^{-1}$ (SEQ) was found before yielding, which is approximately four times the respective values at $72{ }^{\circ} \mathrm{C}\left(0.2 \mathrm{~s}^{-1}\right.$ (SIM), $0.6 \mathrm{~s}^{-1}$ (SEQ)). The strong time dependency was attributed to the dramatic change in moduli in this temperature range, which has been highlighted in DMA tests in previous research $[23,46]$. After the rapid inflation occurs at $t=0.5 \mathrm{~s}$ (T77SIMP6) and $\mathrm{t}=1.4 \mathrm{~s}$ (T77SEQP6), the maximum hoop strain rate reached $6.5 \mathrm{~s}^{-1}$ (T77SIMP6) and $11.8 \mathrm{~s}^{-1}$ (T77SEQP6) respectively, which was $240 \%$ and $290 \%$ higher than that at $72{ }^{\circ} \mathrm{C}$. This finding confirmed the significant change of the viscoelastic behaviour as a function of processing temperature at finite strain [23]. After rapid inflation at $0.5 \mathrm{~s}$ (T77SIMP6) and $1.4 \mathrm{~s}$ (T77SEQP6), the axial strain history showed a significant difference with much more evidence of nonlinear behaviour than the axial strain history at $72{ }^{\circ} \mathrm{C}$. This implied that the axial load from the internal pressure increased more quickly after the onset of inflation and dominated the axial deformation. A maximum axial strain rate of $3.5 \mathrm{~s}^{-1}$ (T77SIMP6) and $5.0 \mathrm{~s}^{-1}$ (T77SEQP6) was exhibited in the nonlinear stage, which was much higher than the maximum possible axial strain rate from elongation of the motor $\left(\sim 1 \mathrm{~s}^{-1}\right)$. At the end of the forming period, an average hoop strain of 2.0 on the outer surface was observed in both processes whilst the average axial strain reached 1.6 1.8.

In Fig. 15, it was found the final hoop strain on the middle surface increased to approximately 3.0 for both T77P6SIM and T77P6SEQ. The maximum hoop strain rate was found to be $9.1 \mathrm{~s}^{-1}$ for the SIM process and $16.8 \mathrm{~s}^{-1}$ for the SEQ process and was $40 \%$ greater than the rate on the external surface (SIM: $6.5 \mathrm{~s}^{-1}$, SEQ: $11.8 \mathrm{~s}^{-1}$ ). The maximum hoop strain rate on the middle surface during inflation at $77^{\circ} \mathrm{C}$ 
Fig. 13 Pressure (P), displacement (D) and force history (F), (a) T77SIMP6, (b) T77SEQP6

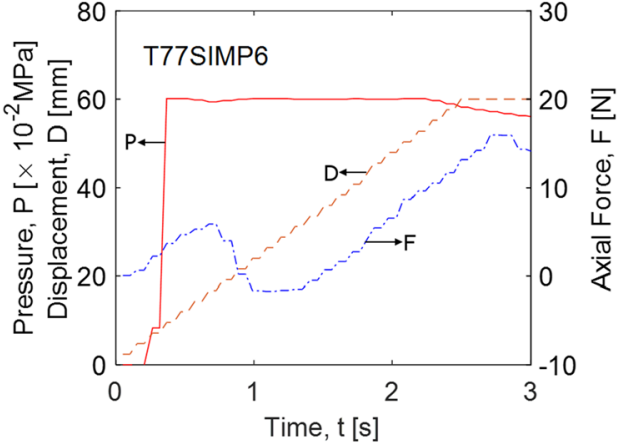

(a)

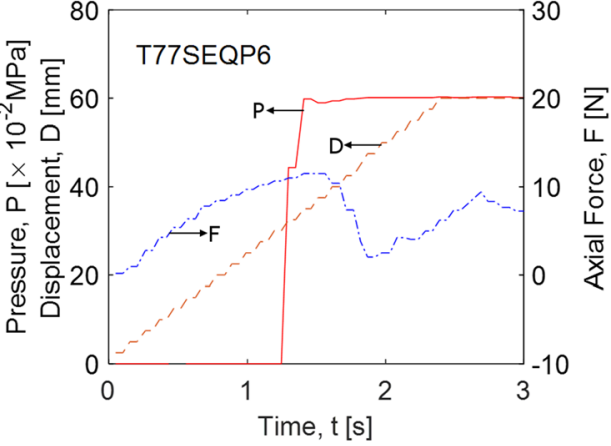

(b) showed a significant increase of $225 \%$ and $300 \%$ compared to the results at $72{ }^{\circ} \mathrm{C}$.

\section{Stress state}

Since the strain is available via the DIC, the evolution of the corresponding stress is also of interest thus providing an opportunity to obtain the constitutive behaviour of PLLA directly from the inflating parison. The ratio between the internal diameter $\left(D_{\text {in }}\right)$ and wall thickness $(t)$ as the tube inflates for all tests was initially calculated to evaluate whether thick walled or thin walled shell theory was the most appropriate for calculating the stress (Fig. 16). As the inflation progressed over time it can be seen the $D_{\text {in }} / t$ increased and that it reached a critical value of 10 at $t=0.95 \mathrm{~s}$ for the T72SIMP6 and at $\mathrm{t}=$ $1.5 \mathrm{~s}$ for T72SEQP6 (Fig. 16(a)). In both cases this time corresponded to the onset of rapid inflation. At $\mathrm{T}_{\mathrm{p}}=77^{\circ} \mathrm{C}$ (Fig. 16(b)), the characteristic time for the change of $D_{i} / t$ to reach greater than 10.0 was $\mathrm{t}=0.55 \mathrm{~s}(\mathrm{~T} 77 \mathrm{SIMP} 6)$ and $\mathrm{t}=$ $1.44 \mathrm{~s}$ (T77SEQP6), approximately 40 50 ms beyond the onset of rapid inflation. The results showed that the tube behaved as a thick-walled shell before inflation with nonuniform hoop stress through the wall thickness and a membrane after the onset of rapid inflation due to the big increase of $\mathrm{D}_{\text {in }} / \mathrm{t}$.

Fig. 14 Strain history of external surface by DIC (purple: $-5 \mathrm{~mm}$, green: $0 \mathrm{~mm}$, magenta: $5 \mathrm{~mm}$ ) and average manual measurement, (a) T77SIMP6, (b) T77SEQP6

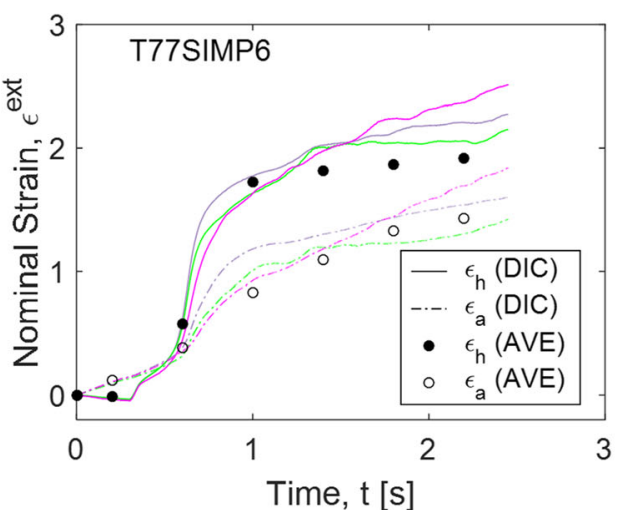

(a)
The case of a slow geometric transformation (T72SIMP6) before $\mathrm{D}_{\mathrm{i}} / \mathrm{t}=10(\mathrm{t}=1.0 \mathrm{~s})$ was selected to calculate the stress history on the middle surface using Eq. (6) (9). The resulting hoop stress from thin-walled shell $\left(\sigma_{\mathrm{h}}{ }^{\text {thn }}\right)$ was slightly higher than that by thick walled-shell $\left(\sigma_{h}{ }^{\text {thk }}\right)$ with a deviation of $\sim 0.3 \mathrm{MPa}$ (Fig. 17(a)). The small deviation between $\sigma_{\mathrm{h}}^{\text {thk }}$ and $\sigma_{\mathrm{h}}{ }^{\text {thn }}$ confirmed that the assumption of membrane state was valid [35]. The axial stress calculated by the thin $\left(\sigma_{\mathrm{a}}{ }^{\mathrm{thn}}\right)$ and thick $\left(\sigma_{\mathrm{a}}{ }^{\text {thk }}\right)$ walled cylinder shell on the middle surface showed a similar stress shift ( $\sim 0.3 \mathrm{MPa})$ (Fig. 17(b)), proving the reliability of the assumption of uniformly distributed axial stress. Based on these investigations, the simplified $\sigma_{\mathrm{h}}{ }^{\text {thn }}$ and $\sigma_{\mathrm{a}}{ }^{\text {thn }}$ (Eq. (6) and (7)) were used in the following section to characterise the average stress state along the cross section in the inflating tube.

Before rapid inflation $(\mathrm{t}=1.1 \mathrm{~s})$ at T72SIMP6, a consistent hoop and axial stress response was observed in Fig. 18a. This was attributed to the consistent hoop and axial strain history (Fig. 15a) at the early stage. The uniaxial stretch for the T72SEQP6 process led to a smaller axial stress compared to the biaxial stretch in the SIM processes. A more rapid increase of hoop stress occurred after the onset of inflation due to the growth of diameter of the tube. In the SIM process, this resulted in the hoop stress being higher than the axial stress. The increase of hoop stress due to rapid inflation introduced an intersection between the hoop and axial stress at $(t=1.8 \mathrm{~s})$ in 
Fig. 15 Strain history on the middle surface, (a) T77SIMP6, (b) T77SEQP6

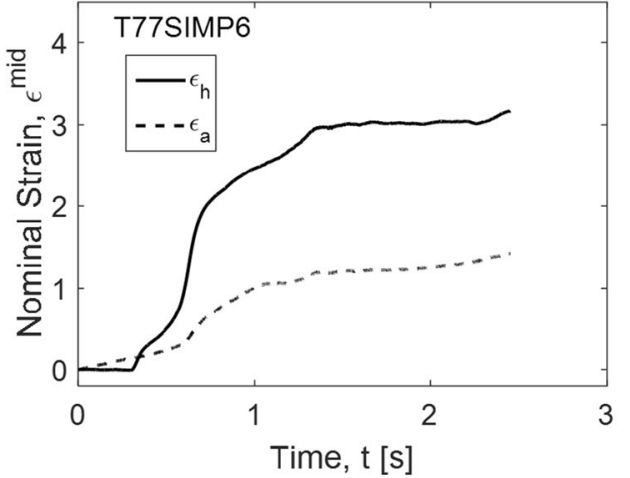

(a)

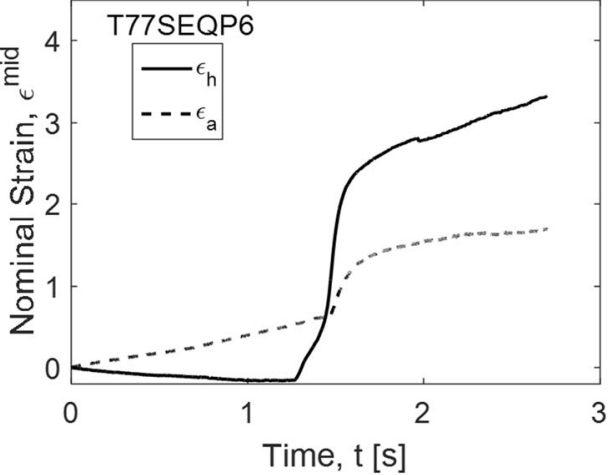

(b) the SEQ process. The final hoop stress $(\sim 25 \mathrm{MPa})$ in the SEQ process was approximately $5 \mathrm{MPa}$ higher than the result in the SIM process $(\sim 20 \mathrm{MPa})$ whilst a similar axial stress ( $\sim 15 \mathrm{MPa}$ ) was found for both modes of deformation. These stresses are similar to those observed from previous studies by the authors on biaxially stretching of planar sheets at similar temperature conditions $\left(\sim 70^{\circ} \mathrm{C}\right)$, e.g. a stress value of $30 \mathrm{MPa}$ was measured from an equal biaxial (EB) test stretched to a final stretch ratio of 2.5 at a constant strain rate of $4 \mathrm{~s}^{-1}$ [23].

A similar stress history was found when the processing temperature increased to $\mathrm{T}_{\mathrm{p}}=77{ }^{\circ} \mathrm{C}$ (Fig. 18b). At T77SIMP6, the axial and hoop stress evolved at a similar level in a very short time period from $t=0.3$ to $0.6 \mathrm{~s}$ due to the early onset of rapid inflation. The axial stress had a slower increase in the SEQ process at uniaxial stretch due to the smaller stiffness at high temperature [23]. The intersection point of hoop and axial stress (SEQ) was observed earlier due to the rapid inflation. After inflation, the hoop stress in the SIM and SEQ continuously increased to reach a final stress of $38 \mathrm{MPa}$ (SIM) and $45 \mathrm{MPa}$ (SEQ). The axial stress experienced a nonlinear rapid increase during inflation but returned to a linear increase after that, giving a final value of $20 \mathrm{MPa}$ (SIM) and $25 \mathrm{MPa}$ (SEQ). The effect from processing temperature by comparing Fig. 18a, $b$ indicated a high stress level at high $T_{p}$ due to the higher stretch of material. A higher stress difference
( $\sim 20 \mathrm{MPa})$ between the hoop and axial direction was observed at high $T_{p}$ compared to the result $(\sim 5 \mathrm{MPa})$ at low $T_{p}$.

The stress-strain relationships on the middle surface curves were created based on the strain and stress history (Fig. 19). As shown in Fig. 19a, isotropic stress-strain relations below a strain of 0.6 was found for T72SIMP6 due to an equal biaxial strain and stress response. For the SIM stretch condition, the strain evolution showed different levels vs. time during the inflation, showing a primary hoop deformation due to the higher inflation rate, leading to a higher axial stress than hoop stress at the same strain. For T72SEQP6 however, no initial coincidence of axial and hoop stress-strain relationship was found due to the deliberate sequential effect of the primary axial stretch. At the same strain, the hoop stress in the SEQ process was higher than that in the SIM process for the initial secondary hoop deformation. For strains less than 1.1, the axial stress (SEQ) was smaller than the hoop stress, corresponding to the stage before the intersection point. After that, the hoop inflation dominated, and the secondary axial stretch introduced higher axial stress than hoop stress.

At $\mathrm{T}_{\mathrm{p}}=77^{\circ} \mathrm{C}$ (Fig. 19b), the stress-strain response for T77SIMP6 displayed similar characteristics as the results at $72{ }^{\circ} \mathrm{C}$, with an overlap in behaviour in the small strain regime $(<0.3)$ and a higher axial stress after that. At a strain level of 2.0, the material behaved softer in the hoop direction at high
Fig. 16 Geometrical evolution of $\left(D_{\text {in }} / t\right)$ in the deformation process, (a) $\mathrm{T}_{\mathrm{p}}=72{ }^{\circ} \mathrm{C}$, (b) $\mathrm{T}_{\mathrm{p}}=77^{\circ} \mathrm{C}$

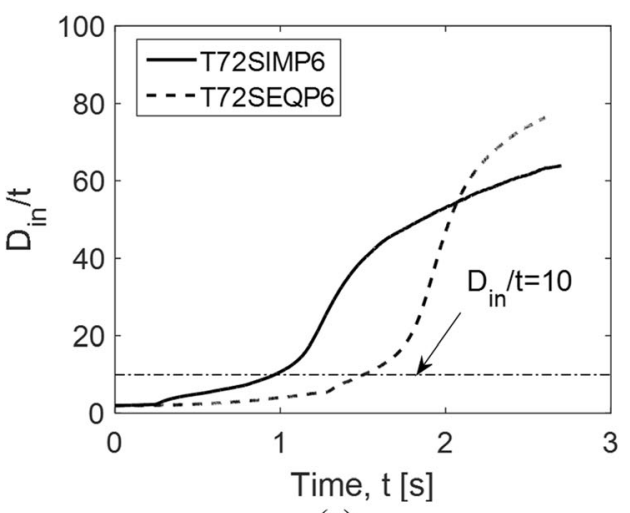

(a)

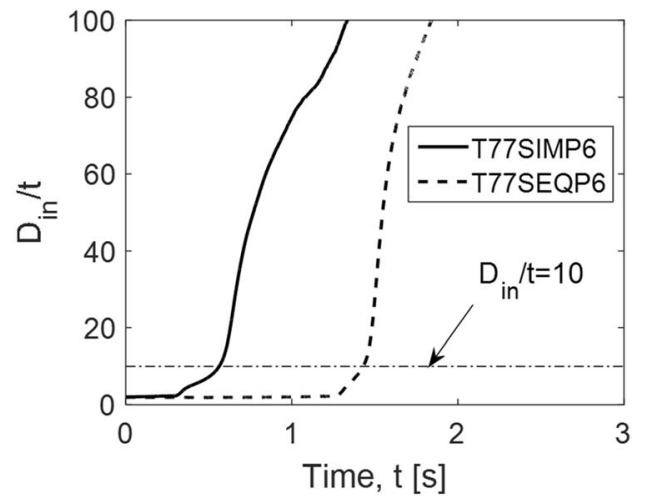

(b) 
Fig. 17 Stress history at T72SIMP6 (a) hoop, (b) axial

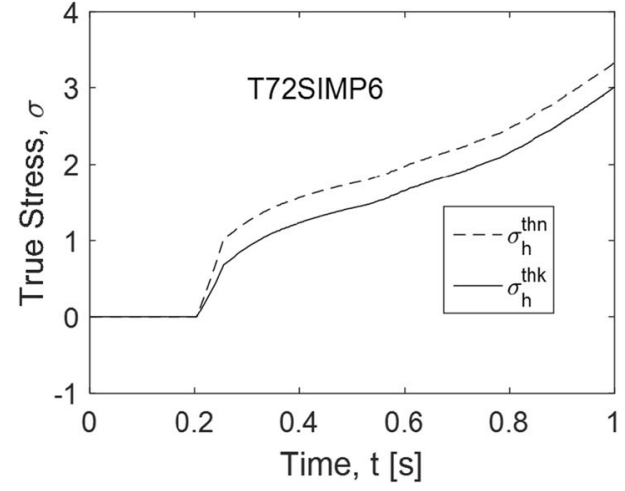

(a)

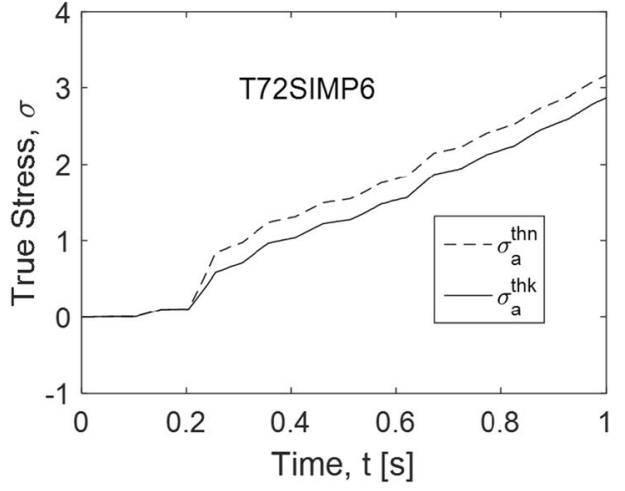

(b) temperature condition, i.e. a hoop stress of $15 \mathrm{MPa}$ at $77^{\circ} \mathrm{C}$ in comparison to $20 \mathrm{MPa}$ at $72{ }^{\circ} \mathrm{C}$ (SIM). A large final hoop strain of 3.7 created a high stress level value of $38 \mathrm{MPa}$ for the test at $77^{\circ} \mathrm{C}$. The early onset of inflation at $77^{\circ} \mathrm{C}$ and the fact that hoop strain rate exceeded the axial strain rate enhanced the sequential effect by secondary stretch in the axial direction. For T77SEQP6, higher hoop stress than the SIM process was observed by the effect of delayed hoop deformation. An intersection between axial and hoop stress curves occurred at a strain level of 0.7 , which was smaller than that $(\sim 1.0)$ in the SEQ process at $72{ }^{\circ} \mathrm{C}$. In general, it can be seen that both the temperature and operational sequence had a great influence on the stress-strain relationship by changing the evolution process and final values.

\section{Discussion}

In this study a new apparatus has been designed and built enabling a new load-controlled test for measuring the stressstrain behaviour of PLLA directly from a parison under blow moulding conditions. It provides valuable data on typical strain rates experienced by the material during forming along with its response when subjected to nonlinear loading paths, which enables a good experimental idealisation of the blow moulding process.

The data presented in this paper highlights the strong influence of temperature and mode of deformation on the blowing characteristics of the PLLA tubes and the corresponding stress-strain behaviour. The sensitivity to temperature is strong with only a $5^{\circ} \mathrm{C}$ increase in temperature from $72{ }^{\circ} \mathrm{C}$ to $77^{\circ} \mathrm{C}$, resulting in an increase in maximum strain rate from $4 \mathrm{~s}^{-1}$ to $17 \mathrm{~s}^{-1}$, an increase in final strain from 2.0 to 3.0 and an increase in final stress from $25 \mathrm{MPa}$ to $45 \mathrm{MPa}$. Since the maximum temperature tested here was $77^{\circ} \mathrm{C}$, additional work is required to evaluate how this effect evolves as the temperature increases further towards the cold crystallisation temperature (maximum forming temperature) of $\sim 100{ }^{\circ} \mathrm{C}[23]$.

Although the influence is not as strong as the temperature, the mode of deformation also has an influence on the blowing characteristics and the stress strain behaviour with an increase in the final stress from $38 \mathrm{MPa}$ to $45 \mathrm{MPa}$ and a reduction in final hoop strain from 3.8 to 3.2 observed for tests conducted at $77^{\circ} \mathrm{C}$ for the two conditions investigated. In this paper only one scenario of a sequential test is provided (initial strain equal to 0.5 ) but further work exploring the influence of the magnitude of the strain in the axial direction on the subsequent behaviour in the hoop direction should be investigated. The other factor that is able to influence the deforming sequence is
Fig. 18 Stress evolution on the middle surface, (a) $\mathrm{T}_{\mathrm{p}}=72{ }^{\circ} \mathrm{C}$, (b) $\mathrm{T}_{\mathrm{p}}=77^{\circ} \mathrm{C}$

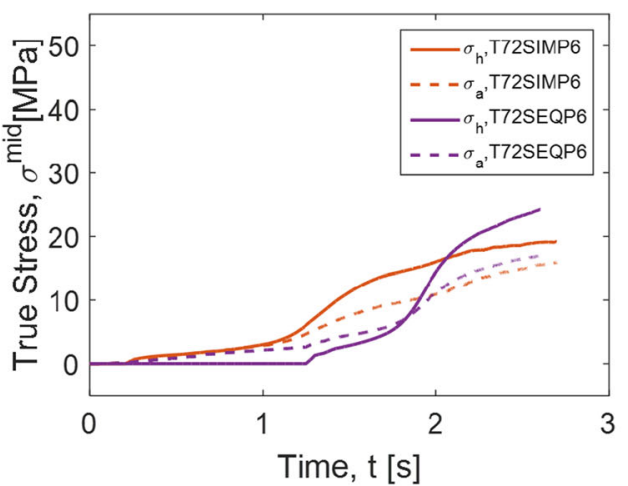

(a)

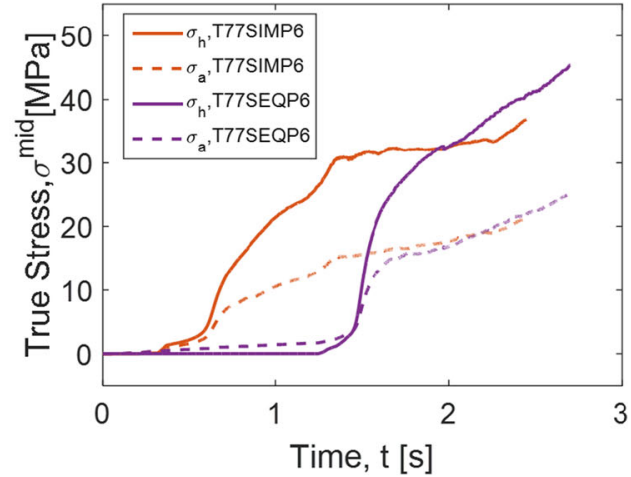

(b) 
Fig. 19 Stress-strain relationship on the middle surface, $(\mathbf{a}) \mathrm{T}_{\mathrm{p}}=$ $72{ }^{\circ} \mathrm{C}$, (b) $\mathrm{T}_{\mathrm{p}}=77^{\circ} \mathrm{C}$

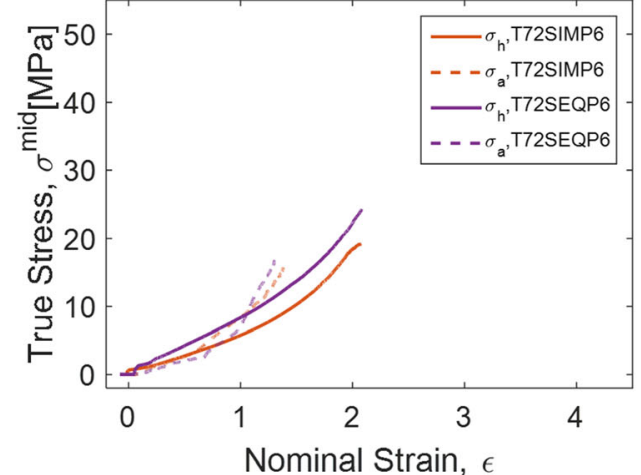

(a)

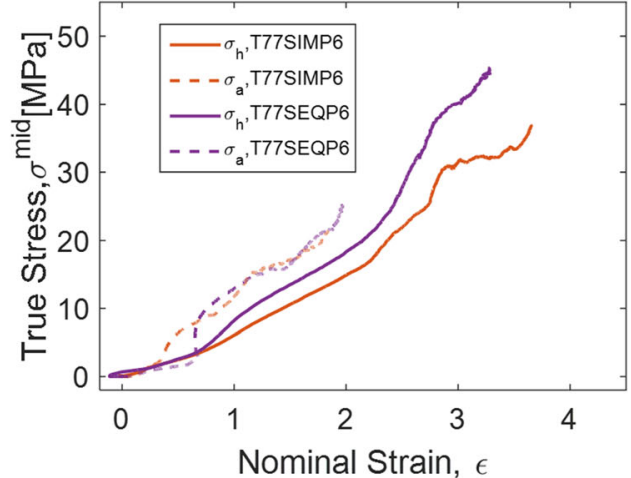

(b) the magnitude of the pressure however this parameter has not been part of this study.

The test method provides a major step forward for characterising the behaviour of PLLA for stretch blow moulding. Whilst previous studies have produced stress strain behaviour at different temperatures and strain rates $[23,45,47$, 48], these have been performed on planar sheets which by default have a different processing history to the tube. In addition, this new test method has the benefit that the properties are measured at conditions directly comparable to stretch blow moulding i.e. with varying strain rates and modes of deformation. One weakness of the test is that due it being a loadcontrolled test the individual contribution of strain rate and temperature is difficult to detect since the strain rate varies significantly during each test and for tests conducted at different temperatures. For this reason, the rig provides important complementary data to the data already presented in the previous study from displacement controlled tests $[23,45,47$, 48]. One anomaly compared to previous published data stress-strain behaviour of PLLA is that no obvious yield point is observed in the stress strain results. This is also due to the load-controlled nature of the test since the material rather than being forced to stretch at a specific speed regulates itself resulting in variable strain rate and no obvious yield point.

One potential criticism of the test method that it was conducted in a water bath given that it is known that hydrolysis and water absorption of PLLA can have a major effect on the mechanical properties [49-52]. However it should be noted that the timescale of the experiment is orders of magnitude smaller than the timescale for hydrolysis to have an influence [53-57]. To verify this, additional experiments have been performed where PLLA tubing was uniaxially stretched after heating in a wet environment for $8 \mathrm{~min}$ (similar to the timescale of the experiments in this paper) and after heating in a dry environment with no significant difference observed [58].

There is an opportunity to further explore the effect of both temperature and mode of deformation by conducting corresponding mechanical property measurements on the blown tubes to assess the influence of the processing history on the modulus, yield and strain at break - although given the dimensions of the blown tubes this provides its own challenges, especially in the hoop direction. With this data in addition to the stress strain data it would be feasible to fit it to a previously developed material model of PLLA [23] and create a forming simulation that has the capability of optimising the parison dimensions and corresponding process conditions to produce a BVS with optimal properties. Even without such a model the raw data presented from the test is a valuable design aid for engineers in the design and manufacture of BVS where the natural draw ratio of a material as a function of temperature is readily available enabling appropriate nominal parison dimensions and processing temperature values to be chosen.

\section{Conclusion}

By a novel experimental setup, a tube forming process for characterising the behaviour of PLLA tubes for stretch blow moulding of BVS has been developed. The experimental scheme was highlighted by the forming process at isothermal conditions in a water bath and measurement of surface strain by digital image correlation (DIC). Operations at designed processing temperature and blowing sequence revealed the deformation behaviour of PLLA materials by the qualitative results on evolution of tube shape and quantitative data of strain and stress. Quantitative results reveal the strong dependence of the stress strain behaviour on strain history experienced by the inflating tube as well as the processing temperature. The unique test rig and methodology developed and the corresponding results offer the ability to characterise materials and understand the influence of processing on material behaviour and provide stress strain data at conditions relevant to forming that is critical for forming simulation development. As a result, the research output has great potential to benefit industry in the development and optimisation of stretch blow moulding of PLLA. 
Funding This project has received funding from the European Union's Horizon 2020 research and innovation programme under the Marie Skłodowska-Curie grant agreement No. 691238 involving Italian National Agency for New Technologies, Energy and Sustainable Economic Development (Italy), University of Warwick (UK), Queen's University Belfast (UK) and California Institute of Technology (US). The $\mathrm{PhD}$ scholarship was funded by Queen's University Belfast and China Scholarship Council.

\section{Compliance with ethical standards}

Conflict of interest The authors declare that they have no conflict of interest.

Open Access This article is licensed under a Creative Commons Attribution 4.0 International License, which permits use, sharing, adaptation, distribution and reproduction in any medium or format, as long as you give appropriate credit to the original author(s) and the source, provide a link to the Creative Commons licence, and indicate if changes were made. The images or other third party material in this article are included in the article's Creative Commons licence, unless indicated otherwise in a credit line to the material. If material is not included in the article's Creative Commons licence and your intended use is not permitted by statutory regulation or exceeds the permitted use, you will need to obtain permission directly from the copyright holder. To view a copy of this licence, visit http://creativecommons.org/licenses/by/4.0/.

\section{References}

1. Regazzoli D, Leone PP, Colombo A, Latib A (2017) New generation bioresorbable scaffold technologies: an update on novel devices and clinical results. J Thorac Dis 9(Suppl 9):S979-S985. https://doi.org/10.21037/jtd.2017.07.104

2. McMahon S, Bertollo N, Cearbhaill EDO et al (2018) Bioresorbable polymer stents: a review of material progress and prospects. Prog Polym Sci 83:79-96. https://doi.org/10.1016/j. progpolymsci.2018.05.002

3. Ang HY, Bulluck H, Wong P et al (2017) Bioresorbable stents: current and upcoming bioresorbable technologies. Int J Cardiol 228:931-939. https://doi.org/10.1016/j.ijcard.2016.11.258

4. Agrawal CM, Haas KF, Leopold DA, Clark HG (1992) Evaluation of poly(L-lactic acid) as a material for intravascular polymeric stents. Biomaterials 13:176-182. https://doi.org/10.1016/01429612(92)90068-Y

5. Grabow N, Schlun M, Sternberg K et al (2005) Mechanical properties of laser cut poly(L-lactide) micro-specimens: implications for stent design, manufacture, and sterilization. J Biomech Eng 127: 25-31. https://doi.org/10.1115/1.1835349

6. Garg S, Serruys P (2009) Biodegradable and non-biodegradable stents. Minerva Cardioangiol 57:537-565

7. Onuma Y, Serruys PW (2011) Bioresorbable scaffold: the advent of a new era in percutaneous coronary and peripheral revascularization? Circulation. https://doi.org/10.1161/CIRCULATIONAHA. 110.971606

8. Ang HY, Bulluck H, Wong P et al (2017) Backup: Bioresorbable stents: current and upcoming bioresorbable technologies. Int $\mathrm{J}$ Cardiol 228:931-939. https://doi.org/10.1016/j.ijcard.2016.11.258

9. Serruys PW, Ormiston J, Van Geuns RJ et al (2016) A polylactide bioresorbable scaffold eluting everolimus for treatment of coronary stenosis 5-year follow-up. J Am Coll Cardiol. https://doi.org/10. 1016/j.jacc.2015.11.060
10. Iqbal J, Onuma Y, Ormiston J et al (2014) Bioresorbable scaffolds: rationale, current status, challenges, and future. Eur Heart J 35:765776

11. Alexy RD, Levi DS (2013) Materials and manufacturing technologies available for production of a pediatric bioabsorbable stent. Biomed Res Int 2013:. https://doi.org/10.1155/2013/137985

12. Martinez AW, Chaikof EL (2011) Microfabrication and nanotechnology in stent design. Wiley Interdiscip Rev Nanomedicine Nanobiotechnology 3(3):256-268. https://doi.org/10.1002/wnan. 123

13. Sugioka K, Cheng Y (2014) Femtosecond laser three-dimensional micro-and nanofabrication. Appl Phys Rev 1. https://doi.org/10. $1063 / 1.4904320$

14. Yu L, Liu H, Xie F et al (2008) Effect of annealing and orientation on microstructures and mechanical properties of polylactic acid. Polym Eng Sci. https://doi.org/10.1002/pen.20970

15. Chapleau N, Huneault MA, Li H (2007) Biaxial orientation of polylactide/thermoplastic starch blends. Int Polym Process 22: 402-409. https://doi.org/10.3139/217.2070

16. Zenkiewicz M, Richert J, Rózański A (2010) Effects of blow molding ratio on mechanical properties of polylactide nanocomposite films. Polimery/Polymers 55:869-876

17. Li Z, Ye L, Zhao X et al (2017) Structure and biocompatibility of highly oriented poly(lactic acid) film produced by biaxial solid hot stretching. J Ind Eng Chem 52:338-348. https://doi.org/10.1016/j. jiec.2017.04.008

18. Glauser T, Gueriguian V, Steichen B, et al (2013) Controlling crystalline morphology of a bioabsorbable stent

19. Ramzipoor K, Alfred, N.K. C, Wang L (2012) Stent fabrication via tubular casting processes. United States Pat. 1-12

20. Sahmel O, Arbeiter D, Siewert S et al (2018) Optimization of manufacturing processes for biodegradable polymeric stents regarding improved mechanical properties. Curr Dir Biomed Eng 4: 583-585. https://doi.org/10.1515/cdbme-2018-0140

21. Grabow N, Bünger CM, Sternberg K et al (2007) Mechanical properties of a biodegradable balloon-expandable stent from poly(Llactide) for peripheral vascular applications. J Med Device 1:84. https://doi.org/10.1115/1.2355683

22. Guerra AJ, San J, Ciurana J (2017) Fabrication of PCL/PLA composite tube for stent manufacturing. Procedia CIRP 65:231-235. https://doi.org/10.1016/j.procir.2017.03.339

23. Wei H, Yan S, Goel S, Menary G (2019) Characterization and modelling the mechanical behaviour of poly ( 1-lactic acid ) for the manufacture of bioresorbable vascular scaffolds by stretch blow moulding. Int J Mater Form

24. Ramachandran K, Miscioscia R, De Filippo G et al (2018) Tube expansion deformation enables in situ synchrotron X-ray scattering measurements during extensional flow-induced crystallization of Poly L-lactide near the glass transition Polymers (Basel): 10 . https://doi.org/10.3390/polym10030288

25. Ailianou A, Ramachandran K, Kossuth MB et al (2016) Multiplicity of morphologies in poly (l-lactide) bioresorbable vascular scaffolds. Proc Natl Acad Sci 113:11670-11675. https://doi. org/10.1073/pnas.1602311113

26. Løvdal A, Andreasen JW, Mikkelsen LP et al (2016) Characterization of biaxial strain of poly(l-lactide) tubes. Polym Int 65:133-141. https://doi.org/10.1002/pi.5040

27. Arbeiter D, Schümann K, Sahmel O et al (2016) The effect of thermal treatment on the mechanical properties of PLLA tubular specimens. Curr Dir Biomed Eng 2:27-29. https://doi.org/10. 1515/cdbme-2016-0009

28. Løvdal ALV, Andreasen JW, Mikkelsen LP et al (2017) Mechanical properties of biaxially strained poly(l-lactide) tubes: strain rate and temperature dependence. J Appl Polym Sci 134:6-11. https://doi. org/10.1002/app.45192 
29. Huang HX, Yin ZS, Liu JH (2007) Visualization study and analysis on preform growth in polyethylene terephthalate stretch blow molding. J Appl Polym Sci. https://doi.org/10.1002/app.25116

30. Menary GH, Armstrong CG (2006) Experimental study and numerical modelling of injection stretch blow moulding of angioplasty balloons. Plast Rubber Compos 35:348-354. https://doi.org/10. 1179/174328906X143877

31. Menary GH, Tan CW, Armstrong CG et al (2010) Validating injection stretch-blow molding simulation through free blow trials. Polym Eng Sci 50:1047-1057. https://doi.org/10.1002/pen.21555

32. Zimmer J, Stommel M (2013) Method for the evaluation of stretch blow molding simulations with free blow trials. IOP Conf Ser Mater Sci Eng 48. https://doi.org/10.1088/1757-899X/48/1/012004

33. Nixon J, Menary GH, Yan S (2016) Free-stretch-blow investigation of poly(ethylene terephthalate) over a large process window. Int $\mathrm{J}$ Mater Form 10(5):1-13. https://doi.org/10.1007/s12289-016-13183

34. Nixon J, Menary GH, Yan S (2017) Finite element simulations of stretch-blow moulding with experimental validation over a broad process window. Int J Mater Form 10:793-809. https://doi.org/10. 1007/s12289-016-1320-9

35. Yan S, Menary G, Nixon J (2017) A novel methodology to characterize the constitutive behaviour of polyethylene terephthalate for the stretch blow moulding process. Mech Mater 104:93-106. https://doi.org/10.1016/j.mechmat.2016.10.006

36. Salomeia Y, Menary GH, Armstrong CG et al (2015) Measuring and modelling air mass flow rate in the injection stretch blow moulding process. Int J Mater Form 9(4):531-545. https://doi.org/ 10.1007/s12289-015-1240-0

37. Piccagli $F$ (2015) Percutaneous Transluminal angioplasty (PTA) balloon stretch blow molding process: development of a numerical model and optimization for lean design. Politecnico di milano

38. Lalli D (2006) Cycle-to-cycle control orthe angioplasty balloon fabrication process

39. Schreier H, Orteu JJ, Sutton MA (2009) Image correlation for shape, motion and deformation measurements: Basic concepts, theory and applications

40. Voyiatzis E, Tsenoglou CJ, Mitsoulis E (2017) Tube inflation of viscoelastic fluids at a constant growth rate. Soft Mater 15:121131. https://doi.org/10.1080/1539445X.2016.1242495

41. Schmidt FM, Rodriguez-Villa A, Agassant F, Bellet M (2000) Analytical models for the inflation of a polymeric tube. Eur J Mech A/Solids 19:89-104. https://doi.org/10.1016/S09977538(00)00150-9

42. Ward IM, Sweeney J (2012) Mechanical properties of solid polymers

43. Schmidt FM, Agassant JF, Bellet M, Desoutter L (1996) Viscoelastic simulation of PET stretch/blow molding process. J Nonnewton Fluid Mech 64:19-42. https://doi.org/10.1016/03770257(95)01420-9

44. Moss DR, Basic MM (2013) Pressure vessel design manual, 4th ed

45. Ou X, Cakmak M (2008) Influence of biaxial stretching mode on the crystalline texture in polylactic acid films. Polymer (Guildf) 49: 5344-5352. https://doi.org/10.1016/j.polymer.2008.09.053
46. Tábi T, Sajó IE, Szabó F et al (2010) Crystalline structure of annealed polylactic acid and its relation to processing. Express Polym Lett. https://doi.org/10.3144/expresspolymlett.2010.80

47. Stoclet G, Seguela R, Lefebvre JM et al (2010) Strain-induced molecular ordering in polylactide upon uniaxial stretching. Macromolecules 43:1488-1498. https://doi.org/10.1021/ ma9024366

48. Zhang X, Schneider K, Liu G et al (2011) Structure variation of tensile-deformed amorphous poly(l-lactic acid): effects of deformation rate and strain. Polymer (Guildf). https://doi.org/10.1016/j. polymer.2011.07.003

49. Yew GH, Mohd Yusof AM, Mohd Ishak ZA, Ishiaku US (2005) Water absorption and enzymatic degradation of poly(lactic acid)/ rice starch composites. Polym Degrad Stab 90:488-500. https://doi. org/10.1016/j.polymdegradstab.2005.04.006

50. Vieira AC, Vieira JC, Ferra JM et al (2011) Mechanical study of PLA-PCL fibers during in vitro degradation. J Mech Behav Biomed Mater 4:451-460. https://doi.org/10.1016/J.JMBBM. 2010.12.006

51. Elsawy MA, Kim K-H, Park J-W, Deep A (2017) Hydrolytic degradation of polylactic acid (PLA) and its composites. Renew Sust Energ Rev 79:1346-1352. https://doi.org/10.1016/J.RSER.2017. 05.143

52. Szegda D (2009) Experimental investigation and computational Modelling of the thermoforming process of thermoplastic starch. Brunel University

53. Zhang N, Yu X, Duan J et al (2018) Comparison study of hydrolytic degradation behaviors between $\alpha^{\prime}$ - and $\alpha$-poly(l-lactide). Polym Degrad Stab 148:1-9. https://doi.org/10.1016/J. POLYMDEGRADSTAB.2017.12.014

54. Tsuji H, Nakahara K (2002) Poly(L-lactide). IX Hydrolysis in acid media J Appl Polym Sci 86:186-194. https://doi.org/10.1002/app. 10813

55. Bleach NC, Tanner KE, Kellomäki M, Törmälä P (2001) Effect of filler type on the mechanical properties of self-reinforced polylactide-calcium phosphate composites. J Mater Sci Mater Med 12:911-915. https://doi.org/10.1023/A:1012884310027

56. Chow WS, Leu YY, Mohd Ishak ZA (2014) Water absorption of poly(lactic acid) Nanocomposites: effects of Nanofillers and Maleated rubbers. Polym - Plast Technol Eng 53:858-863. https:// doi.org/10.1530/EJE-14-0848

57. Tsuji H, Ishida T (2002) Poly(l-lactide). X. Enhanced surface hydrophilicity and chain-scission mechanisms of poly(l-lactide) film in enzymatic, alkaline, and phosphate-buffered solutions. J Appl Polym Sci 87:1628-1633. https://doi.org/10.1002/app.11605

58. Wei H (2019) Charaterisation and Modelling of poly(L-lactic acid) for stretch blow Moulding of Bioresorbable vascular scaffold. Queen's University Belfast

Publisher's note Springer Nature remains neutral with regard to jurisdictional claims in published maps and institutional affiliations. 